Leszek Ziemiański, Anna Duda, Grażyna Żak, Michał Wojtasik, Jarosław Markowski, Agnieszka Wieczorek, Aleksander Kopydłowski

Instytut Nafty i Gazu - Państwowy Instytut Badawczy

\title{
Wykorzystanie spektrometrii rentgenowskiej do oceny sposobu dozowania dodatków modyfikujących proces spalania paliw biogennych
}

\begin{abstract}
W artykule dokonano oceny działania urządzeń dozujących dodatki modyfikujące proces spalania biomasy oraz określono wydajność zastosowanych metod ujednorodniania. Za pomocą spektrometru rentgenowskiego oznaczono w próbkach biomasy zawartości pierwiastków pochodzących z dozowania wybranych dodatków.
\end{abstract}

Słowa kluczowe: biomasa, spektrometria rentgenowska, dodatki uszlachetniające.

\section{The use of X-ray spectrometry for the assessment of a dispensing method for additives modifying the combustion of biogenic fuels}

\begin{abstract}
The article assesses the operation of the devices dosing the additives modifying the biomass and determined the efficiency of the homogenization methods. Using the X-ray spectrometer, the content of elements introduced in selected additives in biomass samples was determined.
\end{abstract}

Key words: biomass, X-ray spectrometry, additives.

\section{Wprowadzenie}

Ograniczona zdolność przyjmowania przez środowisko naturalne zanieczyszczeń pochodzących ze spalania paliw kopalnych skłania społeczeństwo do ich zastępowania odnawialnymi źródłami energii $[4,8]$. Jednym z takich substytutów paliw kopalnych, zwłaszcza węgla kamiennego, jest biomasa - trzecie pod względem wielkości na świecie naturalne źródło energii. Najczęściej spalanym paliwem odnawialnym jest drewno, chociaż coraz częściej stosuje się też inne typy biomasy, takie jak: kora drzew, słoma, trociny, odpady drewna, drewno rozbiórkowe oraz części roślin energetycznych (np. wierzby energetycznej) [7, 10, 11, 12].

Niezależnie od zastosowanej technologii spalania oraz rodzaju biomasy, wykorzystanie jej zamiast paliw kopalnych powoduje znaczące zmniejszenie emisji dwutlenku siarki i tlenków azotu, odpowiedzialnych za występowanie zjawiska kwaśnych deszczy, a także zanieczyszczeń organicznych, w tym wielopierścieniowych węglowodorów aromatycznych.
Natomiast stopień redukcji emisji $\mathrm{CO}_{2}$, podstawowego gazu cieplarnianego, jest uzależniony od wielkości substytucji pierwiastka $\mathrm{C}$ zawartego w paliwie kopalnym (np. w węglu), zgodnie z zasadą, że ilość $\mathrm{CO}_{2}$ pochłaniana przez biomasę w trakcie jej wzrostu jest równa ilości $\mathrm{CO}_{2}$ uwalnianej $\mathrm{w}$ trakcie jej spalania. Zjawisko takie potwierdzone zostało wielokrotnie w testach na instalacjach grzewczych $[3,6]$.

Węgiel kamienny i biomasa mają taki sam podstawowy skład pierwiastkowy. Różni je natomiast zawartość głównych pierwiastków: węgla, wodoru, azotu, tlenu i siarki. Biomasa posiada średnio czterokrotnie więcej tlenu w porównaniu z węglem energetycznym, dwukrotnie mniej węgla, a także mniej siarki, azotu i popiołu ( $5 \div 10$ razy mniej, w zależności od rodzaju biomasy).

Właściwości fizykochemiczne biomasy powodują, że jest ona paliwem trudnym technologicznie, znacznie różniącym się od węgla spalanego w kotłach energetycznych $[1,2]$. 
Podstawowe różnice między tymi paliwami to:

- wyższa zawartość wilgoci w surowej biomasie, która wpływa negatywnie na efektywność procesu spalania,

- wyższa zawartość części lotnych $(65 \div 80 \%)$, zmieniająca warunki zapłonu i spalania,

- niższa wartość opałowa surowej biomasy,

- jakościowo zbliżony skład chemiczny, lecz występujące różnice w składzie ilościowym.

Konsekwencją tych właściwości jest wysoka reaktywność biomasy, co wymusza konieczność stosowania odpowiednich rozwiązań zabezpieczających jej efektywne energetyczne przetworzenie (zwłaszcza w przypadku procesu spalania rozwiązania te muszą zapewnić warunki zupełnego spalania wydzielających się w krótkim czasie lotnych produktów rozkładu biomasy). Działaniem takim może być m.in. zastosowanie dodatków modyfikujących proces spalania biomasy. Mają one za zadanie zarówno usprawnienie procesu spalania, jak również obniżenie emisji substancji szkodliwych.

Według danych literaturowych jako dodatki poprawiające proces spalania stosowane są substancje zawierające metale, np.: Fe, K, Ca, Mg, Si, Al.

W celu poprawy procesu spalania biomasy oraz ograniczenia emisji toksycznych składników spalin, w Instytucie Nafty i Gazu - Państwowym Instytucie Badawczym, w ramach projektu współfinansowanego ze środków NCBiR, przeprowadzono badania laboratoryjne zmierzające do opracowania składu dodatków modyfikujących proces spalania biomasy i sprawdzenia efektywności ich działania w zakresie ograniczania emisji toksycznych składników spalin.

\section{Część doświadczalna}

\section{Materiaty}

Jako paliwo bazowe stosowano trociny drzewne o właściwościach podanych w tablicy 1 .

Do badań oceny działania urządzeń dozujących oraz wydajności zastosowanych metod ujednorodniania wybrano trzy dodatki zawierające związki żelaza, potasu i magnezu, które modyfikują proces spalania biomasy i ograniczają emisję szkodliwych substancji. Dodatki rozcieńczono w wysoko wrzącym rozpuszczalniku alifatycznym. Poniżej przedstawiono krótki opis zastosowanych dodatków.

\section{DMS 1}

W skład dodatku DMS 1 wchodzą związki żelaza, głównie tlenki żelaza zdyspergowane w rozpuszczalniku organicznym. Dodatek DMS 1 został zsyntezowany w INiG - PIB. Metoda otrzymywania polega na zmieszaniu wodnych roztworów dwu- i trójwartościowych soli żelaza w obecności amoniaku, dodaniu wysoko wrzącego rozpuszczalnika organicznego i roztworu dyspergatora (mieszanina nienasyconych kwasów tłuszczowych). Mieszaninę ogrzewano pod chłodnicą zwrotną przez 12 godzin. Po zakończeniu reakcji rozdzielono fazę wodną od organicznej. Fazę organiczną poddano procesowi utleniania przez dodanie roztworu nadtlenku wodoru i ponownie rozdzielono fazy: wodną i organiczną. Fazę organiczną przedestylowano w celu usunięcia rozpuszczalnika i resztek wody. Pozostałość przefiltrowano, uzyskując produkt końcowy. Zawartość żelaza w dodatku, wyznaczona metodą ICP-OES, wynosiła $15 \% \mathrm{~m} / \mathrm{m}$.
Tablica 1. Właściwości paliwa bazowego stosowanego do badań

\begin{tabular}{|c|c|}
\hline Właściwość & Wynik \\
\hline Zawartość wodoru [\% $(\mathrm{m} / \mathrm{m})]$ & 5,70 \\
\hline Wartość opałowa $[\mathrm{kJ} / \mathrm{kg}]$ & 17826 \\
\hline Zawartość siarki $[\%(\mathrm{~m} / \mathrm{m})]$ & $<0,01$ \\
\hline Zawartość chloru $[\%(\mathrm{~m} / \mathrm{m})]$ & 0,016 \\
\hline Zawartość wilgoci $[\%(\mathrm{~m} / \mathrm{m})]$ & 13,60 \\
\hline Zawartość popiołu $[\%(\mathrm{~m} / \mathrm{m})]$ & 0,495 \\
\hline $\begin{array}{l}\text { Temperatury charakterystyczne topliwości } \\
\text { popiołu w atmosferze redukującej/utleniającej: } \\
\text { - temperatura skurczu, SST }\left[{ }^{\circ} \mathrm{C}\right] \\
\text { - temperatura deformacji, DT }\left[{ }^{\circ} \mathrm{C}\right] \\
\text { - temperatura półkuli, HT }\left[{ }^{\circ} \mathrm{C}\right] \\
\text { - temperatura płynięcia, FT }\left[{ }^{\circ} \mathrm{C}\right]\end{array}$ & $\begin{array}{c}740 / 660 \\
800 / 1260 \\
1450 / 1360 \\
1460 / 1370\end{array}$ \\
\hline \multicolumn{2}{|l|}{ Zawartość tlenków w popiele [\% $(\mathrm{m} / \mathrm{m})]$} \\
\hline $\mathrm{SiO}_{2}$ & 6,46 \\
\hline $\mathrm{Fe}_{2} \mathrm{O}_{3}$ & 0,26 \\
\hline $\mathrm{Al}_{2} \mathrm{O}_{3}$ & 1,06 \\
\hline $\mathrm{Mn}_{3} \mathrm{O}_{4}$ & 0,93 \\
\hline $\mathrm{TiO}_{2}$ & 0,62 \\
\hline $\mathrm{CaO}$ & 22,07 \\
\hline $\mathrm{MgO}$ & 6,06 \\
\hline $\mathrm{SO}_{3}$ & 0,00 \\
\hline $\mathrm{P}_{2} \mathrm{O}_{5}$ & 0,00 \\
\hline $\mathrm{Na}_{2} \mathrm{O}$ & 0,00 \\
\hline $\mathrm{K}_{2} \mathrm{O}$ & 24,80 \\
\hline $\mathrm{BaO}$ & 1,59 \\
\hline $\mathrm{SrO}$ & 0,00 \\
\hline $\mathrm{Cl}$ (chlorki) & 0,89 \\
\hline $\mathrm{CO}_{2}$ (węglany) & - \\
\hline SUMA & 64,73 \\
\hline
\end{tabular}




\section{DMS 2}

Dodatek DMS 2 zawiera sole potasu rozpuszczone w mieszaninie nienasyconych kwasów thuszczowych. DMS 2 zsyntezowano w INiG - PIB. Związki potasu otrzymano w reakcji odpowiednich tlenków lub wodorotlenków potasu z mieszaniną kwasów tłuszczowych, głównie kwasu oleinowego. Proces syntezy prowadzono pod chłodnicą zwrotną w układzie dwufazowym ksylen/woda, w obecności katalizatora kwasowego (kwas octowy) i czynnika zwiększającego wzajemną rozpuszczalność międzyfazową. Produkt końcowy otrzymywano po usunięciu wody metodą destylacji azeotropowej i oddestylowaniu rozpuszczalnika pod obniżonym ciśnieniem. Uzyskane sole potasu rozpuszczano w mieszaninie nienasyconych kwasów tłuszczowych. Zawartość potasu w produkcie końcowym, wyznaczona metodą ICP-OES, wynosiła $2,3 \% \mathrm{~m} / \mathrm{m}$.

\section{DMS 3}

Dodatek DMS 3 zawiera sole magnezu rozpuszczone w mieszaninie nienasyconych kwasów thuszczowych. DMS 3 zsyntezowano w INiG - PIB. Związki magnezu otrzymano w reakcji odpowiednich tlenków lub wodorotlenków magnezu z mieszaniną kwasów tłuszczowych, głównie kwasu oleinowego. Proces syntezy prowadzono pod chłodnicą zwrotną, w układzie dwufazowym ksylen/woda, w obecności katalizatora kwasowego (kwas octowy) i czynnika zwiększającego wzajemną rozpuszczalność międzyfazową. Produkt końcowy otrzymywano po usunięciu wody metodą destylacji azeotropowej i oddestylowaniu rozpuszczalnika pod obniżonym ciśnieniem. Uzyskane sole magnezu rozpuszczano w mieszaninie nienasyconych kwasów thuszczowych. Zawartość magnezu w produkcie końcowym, wyznaczona metodą ICP-OES, wynosiła $4,9 \% \mathrm{~m} / \mathrm{m}$.

\section{Metoda fluorescencji rentgenowskiej}

Badania zawartości pierwiastków pochodzących z dozowanych dodatków w próbkach biomasy wykonano w spektrometrze rentgenowskim z dyspersją fali Axios Petro firmy PANalitycal [5].

Zasada działania spektrometrów rentgenowskich polega na wybiciu elektronów z wewnętrznych powłok elektronowych za pomocą lampy rentgenowskiej o dużej energii, a następnie zapełnieniu powstałych braków przez elektrony z wyższych powłok, czemu towarzyszy emisja promieniowania rentgenowskiego o charakterystycznej dla danego pierwiastka energii [9].

Metoda fluorescencyjnej analizy rentgenowskiej XRF (ang. X-Ray Fluorescence Analysis) korzysta ze spektrometrów dwóch rodzajów:
- spektrometrów dyspersji energii EDXRF (ang. Energy Dispersive X-Ray Fluorescence Analysis),

- spektrometrów dyspersji długości fali WDXRF (ang. Wavelength Dispersive X-Ray Fluorescence Analysis).

Spektrometry te różnią się układem detekcji. Spektrometr EDXRF ma detektor, który pozwala na pomiar różnych energii promieniowania padającego na próbkę. Spektrometr WDXRF wykorzystuje kryształ analizatora do dyspersji długości fali promieniowania. Rodzaj analizowanych pierwiastków i granica ich wykrywalności zależą od stosowanego spektrometru. W przypadku spektrometru EDXRF można analizować pierwiastki od $\mathrm{Na}$ do $\mathrm{U}$, a przy użyciu spektrometru WDXRF - pierwiastki od Be do U.

\section{Wyniki badań}

Uszlachetnienie biomasy odpowiednimi dodatkami wymagało zaprojektowania i przygotowania właściwej instalacji dozującej dodatki oraz równomiernie rozprowadzającej je w masie paliwa, a także opracowania metody oceny jednorodności dodatków w biomasie. Analizując drogę biomasy z miejsca jej zbioru do odbiorcy będącego wytwórcą energii elektrycznej lub ciepła, stwierdzono, że najmniejsze nakłady inwestycyjne związane z wdrożeniem do stosowania dodatków do biomasy będą konieczne w przypadku instalacji przeznaczonych do kompaktowania (peletowanie lub brykietowanie) biomasy. Na użytek oceny działania urządzeń dozujących oraz wydajności zastosowanych metod ujednorodniania wykorzystano metodę oznaczania zawartości pierwiastków techniką spektrometrii rentgenowskiej.
W celu opracowania koncepcji i założeń technologicznych wprowadzenia dodatków do stałych paliw biogennych przeanalizowano strukturę dozowanych dodatków i zabezpieczenia konieczne dla bezpiecznej pracy układu dozującego oraz pracowników obsługujących proces dozowania.

Środki uszlachetniające pełniące funkcję modyfikatorów procesu spalania biomasy to dodatki ciekłe rozpuszczone lub zdyspergowane w wysoko wrzącym rozpuszczalniku alifatycznym. Muszą być rozpylone, aby w łatwy i jednorodny sposób wymieszały się z biomasą. Rozpylony rozpuszczalnik alifatyczny w kontakcie z powietrzem może tworzyć mieszaninę wybuchową, co stanowi zagrożenie dla instalacji oraz pracowników obsługujących procesy dozowania i brykietowania. Aby wyeliminować zagrożenia, do mieszalnika zamiast powierza dostarczano azot. 
W celu wykonania testów prototypowych elementów instalacji dozowania dodatków ciekłych, Agencja Rozwoju Przedsiębiorczości Sp. z o.o. (partner projektu) zaprojektowała i wykonała prototyp dozownika, a INiG - PIB przygotował niezbędne dodatki.

Prototyp dozownika składał się z układu rozpylającego roztwory, zbiornika z mieszadłem, układu węży i zaworów oraz układu wentylacji. Przygotowano układ rozpylający roztwory za pomocą sprężonego azotu. W tym celu wykonano stanowisko składowania butli z azotem, zastosowano szereg reduktorów, przepływomierzy oraz zaworów odcinających. Dla zapewnienia bezpieczeństwa stanowisko do dozowania dodatków rozpuszczonych lub zdyspergowanych w rozpuszczalniku organicznym wyposażono w przenośne urządzenie do pomiaru granicy wybuchowości substancji w powietrzu. W celu regulacji przepływu strumienia rozpylanej cieczy zamontowano reduktor oraz manometr mierzący ciśnienie w układzie podawania powietrza. Wykonano zbiornik o objętości $100 \mathrm{dm}^{3} \mathrm{z}$ mieszadłem napędzanym silnikiem elektrycznym. Układ rozpylający roztwory dodatków połączono ze zbiornikiem za pomocą węży i zaworów. Wykonano system wentylacji układu (wyposażony w filtr z węglem aktywnym), który zapewnił odciągnięcie oparów ze strefy dozowania. Poziomy dozowania rozpuszczonych dodatków ciekłych wyznaczono na podstawie testów laboratoryjnych. Pojedyncza próba dozowania miała na celu uszlachetnienie $600 \mathrm{~kg}$ trocin drzewnych. Dla każdego dodatku wykonano po 2 powtórzenia testów dozowania, a następnie sprawdzono jednorodność uszlachetnionych paliw, oznaczając w zbrykietowanej biomasie zawartości wybranych pierwiastków pochodzących z wprowadzanych dodatków.

W równych odstępach czasu pobierano próbki uszlachetnianej biomasy, w których określano zawartości wybranych pierwiastków pochodzących z dozowanych dodatków. Zmielone próbki biomasy wprowadzano do metalowej matrycy i umieszczano w prasie hydraulicznej, poddając naciskowi około 13 ton przez okres 20 minut. Tak przygotowaną pastylkę wkładano do kubka pomiarowego i wykonywano rejestrację widma fluorescencji rentgenowskiej. Badania prowadzono na spektrometrze rentgenowskim z dyspersją fali Axios Petro firmy PANalitycal. Zawartość poszczególnych pierwiastków wyznaczono przez pomiar ilości zliczeń i odniesienie ich do krzywych wzorcowych. W tablicy 2 zamieszczono oznaczone zawartości pierwiastków w pobranych próbkach biomasy bazowej i uszlachetnionej dodatkami modyfikującymi jej proces spalania oraz ograniczającymi emisję toksycznych składników spalin.

Oznaczone w próbkach biopaliw zawartości wybranych pierwiastków pochodzących z dozowanych dodatków wskazują na niewielkie rozbieżności w dokładności dozowania, ale mogą również wynikać z ograniczonej dokładności techniki spektrometrii rentgenowskiej i niejednorodności badanego materiału (odchylenie standardowe $0,0003 \div 0,0009$ ).

Tablica 2. Wyniki badań zawartości pierwiastków w próbkach biomasy bazowej i uszlachetnionej modyfikatorami spalania

\begin{tabular}{|c|c|c|c|c|c|c|}
\hline & \multirow{2}{*}{ Metal } & \multicolumn{3}{|c|}{ Zawartość $[\%(\mathrm{~m} / \mathrm{m})]$} & \multirow{2}{*}{ Średnia } & \multirow{2}{*}{$\begin{array}{l}\text { Odchylenie } \\
\text { standardowe }\end{array}$} \\
\hline & & próbka 1 & próbka 2 & próbka 3 & & \\
\hline \multirow{3}{*}{ Paliwo bazowe } & $\mathrm{Fe}$ & 0,0006 & - & - & - & - \\
\hline & $\mathrm{K}$ & 0,1070 & - & - & - & - \\
\hline & $\mathrm{Mg}$ & 0,0219 & - & - & - & - \\
\hline DMS 1 & $\mathrm{Fe}$ & 0,0064 & 0,0074 & 0,0059 & 0,0066 & 0,0006 \\
\hline DMS 2 & K & 0,1127 & 0,1120 & 0,1124 & 0,1124 & 0,0003 \\
\hline DMS 3 & $\mathrm{Mg}$ & 0,0296 & 0,0305 & 0,0290 & 0,0293 & 0,0009 \\
\hline
\end{tabular}

\section{Podsumowanie}

Biorąc pod uwagę:

- dozowanie dodatków do materiału sypkiego wstępnie rozdrobnionego (trociny - surowiec do produkcji brykietów),

- wykorzystanie prototypowego urządzenia dozującego,
- niejednorodność materiału badawczego,

- dokładność spektrometrii rentgenowskiej

wyznaczony eksperymentalnie przedział dokładności dozowania można uznać za zadowalający.

Prosimy cytować jako: Nafta-Gaz 2016, nr 1, s. 45-49, DOI: 10.18668/NG2016.01.06

Artykuł nadesłano do Redakcji 12.06.2015 r. Zatwierdzono do druku 23.07.2015 r.

Artykuł powstał na podstawie pracy badawczej pt. Opracowanie pakietu dodatków wielofunkcyjnych do stałych paliw biogennych i sposobu wprowadzenia go do paliw - praca INiG - PIB na zlecenie NCBiR, nr umowy INNOTECH-K1/IN1/66/158900/NCBR/12. 


\section{Literatura}

[1] Baxter L.: Biomass-coal co-combustion: opportunity for affordable renewable energy. Fuel 2005, vol. 84, s. 1295-1302.

[2] Błasiak W.: Techniczne możliwości wspótspalania węgla $z$ duża ilościa biomasy. Czysta Energia 2008, vol. 79, nr 5, s. 32-37.

[3] Demirbas A.: Potential applications of renewable energy sources, biomass combustion problems in boiler power systems and combustion related environmental issues. Progress in Energy and Combustion Science 2005, vol. 31, s. 171-192.

[4] Duda A., Ziemiański L.: Charakterystyka jakościowa wybranych komponentów paliw statych. Przemysł Chemiczny 2012, nr 6, s. 1279-1282.

[5] Kopydłowski A., Wieczorek A., Krasodomski M.: Problemy z przygotowaniem próbek biomasy do oznaczania składu pierwiastkowego technika spektrometrii rentgenowskiej. Nafta-Gaz 2014, nr 9, s. 623-631.

[6] Kowalczyk-Juśko A.: Popiół z różnych roślin energetycznych. Proceedings of EC Opole 2009, nr 3, s. 159-164.

[7] Niu Y., Tan H., Wang X., Liu Z., Liu H., Liu Y., Xu T.: Study on fusion characteristics of biomass ash. Bioresource Technology 2010, vol. 101, s. 9373-9381.

[8] Ściążko M., Zuwała J., Pronobis M.: Zalety $i$ wady wspótspalania biomasy w kotłach energetycznych na tle doświadczeń

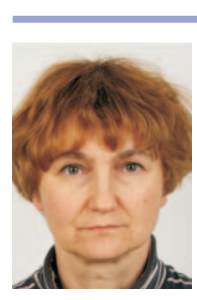

Mgr inż. Anna DUDA

Specjalista badawczo-techniczny w Zakładzie Paliw i Procesów Katalitycznych.

Instytut Nafty i Gazu - Państwowy Instytut Badawczy ul. Lubicz 25 A

31-503 Kraków

E-mail: anna.duda@inig.pl

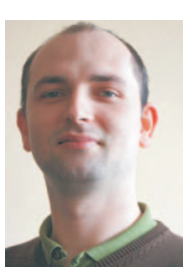

Mgr Michał WOJTASIK

Asystent w Zakładzie Dodatków i Nowych

Technologii Chemicznych.

Instytut Nafty i Gazu - Państwowy Instytut Badawczy

ul. Lubicz 25 A

31-503 Kraków

E-mail: michal.wojtasik@inig.pl

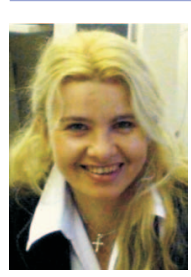

Mgr inż. Agnieszka WIECZOREK

Specjalista badawczo-techniczny w Zakładzie

Analiz Naftowych, kierownik Pracowni Analiz

Instrumentalnych.

Instytut Nafty i Gazu - Państwowy Instytut Badawczy

ul. Lubicz 25 A, 31-503 Kraków

E-mail: agnieszka.wieczorek@inig.pl eksploatacyjnych pierwszego roku wspótspalania biomasy na skale przemysłową. Energetyka 2006, nr 3, s. 207-220.

[9] Skupio R.: Wykorzystanie przenośnego spektrometru XRF do pomiarów składu chemicznego skat. Nafta-Gaz 2014, nr 11, s. 771-777.

[10] Vassilev S. V., Baxter D., Vassileva Ch. G.: An overview of the behaviour of biomass during combustion: Part I. Phase-mineral transformations of organic and inorganic matter. Fuel 2013, vol. 112, s. 391-449.

[11] Vassilev S. V., Baxter D., Vassileva Ch. G.: An overview of the behaviour of biomass during combustion: Part II. Ash fusion and ash formation mechanisms of biomass types. Fuel 2014, vol. 177, s. 152-183.

[12] Xiang Fang, Li Jia: Experimental study on ash fusion characteristics of biomass. Bioresource Technology 2012, vol. 104, s. 769-774.

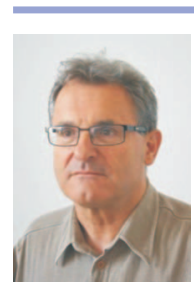

Dr Leszek ZIEMIAŃSKI

Adiunkt; kierownik Zakładu Dodatków i Nowych

Technologii Chemicznych.

Instytut Nafty i Gazu - Państwowy Instytut Badawczy ul. Lubicz 25 A

31-503 Kraków

E-mail: leszek.ziemianski@inig.pl

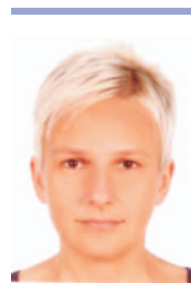

Dr Grażyna ŻAK

Adiunkt w Zakładzie Dodatków i Nowych

Technologii Chemicznych.

Instytut Nafty i Gazu - Państwowy Instytut Badawczy ul. Lubicz 25 A

31-503 Kraków

E-mail: grazyna.zak@inig.pl

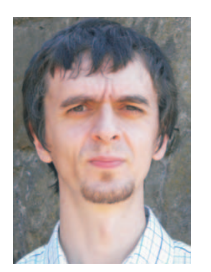

Mgr inż. Jarosław MARKOWSKI

Asystent w Zakładzie Dodatków i Nowych

Technologii Chemicznych.

Instytut Nafty i Gazu - Państwowy Instytut Badawczy

ul. Lubicz 25 A

31-503 Kraków

E-mail: jaroslaw.markowski@inig.pl

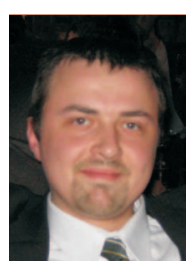

Mgr inż. Aleksander KOPYDŁOWSKI

Specjalista inżynieryjno-techniczny w Zakładzie Analiz Naftowych.

Instytut Nafty i Gazu - Państwowy Instytut Badawczy ul. Lubicz 25 A

31-503 Kraków

E-mail: aleksander.kopydlowski@inig.pl 